\title{
Q1 Pesquisa de coliformes em compostagem de resíduos de hortaliças com a utilização de diferentes substratos
}

Francisco Rafael Martins Soto ${ }^{1}$

Susi Leme de Moura²

Lucas Pinheiro Nóbrega ${ }^{3}$

Sergio Santos de Azevedo 4

\section{Resumo}

Objetivou-se avaliar a redução ou a eliminação de bactérias do grupo coliforme em um sistema de compostagem de resíduos sólidos de hortaliças (RSH) com os substratos serragem e capim seco. Foram realizados dois tratamentos com três repetições em cada um. No primeiro tratamento, foram utilizados RSH e serragem na proporção de 6:1. No segundo, foi utilizada a mesma proporção do primeiro, porém o substrato foi o capim seco. Para a pesquisa das bactérias do grupo coliforme foram efetuadas 16 coletas em cada canteiro. Analisou-se também a temperatura e produção de chorume. Os resultados revelaram que a utilização dos substratos serragem ou capim seco foi incapaz de reduzir coliformes totais. Entre a terceira e a sétima semana, houve redução de aproximadamente $50 \%$ dos coliformes termotolerantes para o substrato serragem e, entre a terceira e a sexta semana, o substrato capim seco foi capaz de reduzir em aproximadamente $40 \%$ os coliformes termotolerantes. As temperaturas foram inferiores a $40{ }^{\circ} \mathrm{C}$ durante as dezesseis semanas do experimento para os dois tipos de substratos.

Palavras-chave: Coliformes totais e termotolerantes. Serragem. Capim seco. Temperatura.

\section{Introdução}

Compostagem pode ser definida como uma decomposição controlada, exotérmica e bio-oxidativa de materiais de origem orgânica por micro-organismos autóctones, em um ambiente úmido, aquecido e aeróbio, com produção de dióxido de carbono, água, minerais e uma matéria orgânica estabilizada, definida como composto (BARREIRA, PHILIPPI JUNIOR, RODRIGUES, 2006).

Esse composto quando empregado no solo proporciona benefícios agronômicos, como elevação do $\mathrm{pH}$, redução da acidez potencial e aumento na disponibilidade de macronutrientes, além de representar um benefício de ordem social, devido à disposição final menos impactante no ambiente (RODRIGUES et al., 2011).

Dentre as práticas previstas para o tratamento de resíduos sólidos de hortaliças (RSH), o processo de compostagem efetuado pela agroindústria tem demonstrado resultados divergentes para a

1 Instituto Federal de Educação, Ciência e Tecnologia de São Paulo, Campus São Roque, docente. São Roque, São Paulo, Brasil. sotofrm@ifsp.edu.br. Rodovia Prefeito Quintino de Lima, 2100, São Roque (SP), CEP 18136-540.

2 Instituto Federal de Educação, Ciência e Tecnologia de São Paulo, Campus São Roque, discente. São Roque, São Paulo, Brasil. susi.leme@gmail.com.

3 Instituto Federal de Educação, Ciência e Tecnologia de São Paulo, Campus São Roque, discente. São Roque, São Paulo, Brasil. lucasnobrega@live.com.

4 Universidade Federal de Campina Grande, docente. sergio@vps.fmvz.usp.br. 
produção de chorume e para os valores da temperatura do sistema, principalmente quando se utilizam diferentes substratos (MALDONADO et al., 2015).

A utilização de substratos como capim seco e/ou serragem na compostagem tem como objetivo alcançar as características desejadas para o seu desenvolvimento, como fontes de carbono para o crescimento microbiano, além da manutenção da umidade com valores próximos a 70 \% (VALENTE et al., 2011). Esses resíduos devem ajustar a umidade, normalmente muito alta em RSH, devido à produção de chorume que é estabelecida. Ademais, esses substratos também devem melhorar a relação carbono/nitrogênio ou a textura da massa em compostagem.

A correta escolha e a utilização do substrato em proporções adequadas podem ser determinantes para se atingir o objetivo sanitário e ambiental da compostagem, que é reduzir ou eliminar bactérias patogênicas, como as do grupo coliforme, e bio-disponibilizar os nutrientes no solo (SUNADA et al., 2015).

Investigações têm demonstrado que quanto maior for a quantidade de compostos de hidratos de carbono na compostagem, associados a substratos de preenchimento de qualidade, mais intensa será a atividade microbiana; consequentemente, será estabelecida a exotermia na fase inicial do processo (VALENTE et al., 2014).

Em uma investigação que avaliou a influência da temperatura no processo de compostagem de resíduos orgânicos domiciliares com elevada porcentagem de RSH sobre a redução de Escherichia coli, Salmonella sp., ovos de helmintos e vírus entéricos além da contagem de bactérias heterotróficas, foi constatada oscilação nas contagens de $E$. coli e de bactérias heterotróficas, mesmo após a fase termofílica. Por outro lado, não foi detectada a presença de Salmonella sp., vírus entéricos nem de ovos viáveis de helmintos ao final do processo (HECK et al., 2013).

Em um sistema que envolveu o tratamento de dejeto de bovino por compostagem, contaminado por Escherichia coli shigatoxigênica, o sistema foi capaz de eliminar o micro-organismo, diminuindo o risco de contaminação ambiental e a disseminação do patógeno (GONÇALVES; MARIN, 2007).

$O$ processo de compostagem de carcaças de frangos mostrou-se eficiente na eliminação ou redução de micro-organismos como Salmonella e coliformes termotolerantes em níveis compatíveis com o que é exigido pela legislação (SANCHUKI et al., 2011; PAIVA et al. 2012a).

Este trabalho teve por objetivo avaliar a redução ou a eliminação de bactérias do grupo coliforme em um sistema de compostagem de RSH com dois diferentes substratos: serragem e capim seco.

\section{Material e métodos}

O trabalho foi realizado na área experimental do Instituto Federal de Educação, Ciência e Tecnologia de São Paulo, Campus São Roque, no período compreendido entre 30 de abril e 12 de agosto de 2015, equivalente a 105 dias ou 16 semanas. Foram realizados dois tratamentos com três repetições em cada um, na forma de canteiros, do tipo fatorial $6 \times 3 \times 2$, conforme Figura 1 . 
Figura 1. Representação esquemática do desenho experimental de compostagem de resíduos sólidos de hortaliças (RSH) com dois diferentes substratos: serragem e capim seco.

\begin{tabular}{|l|c|c|c|}
\hline \multirow{4}{*}{$\begin{array}{c}\text { Tanque para retenção de } \\
\text { chorume }\end{array}$} & RSH e serragem & RSH e serragem & RSH e serragem \\
\cline { 2 - 4 } & \multicolumn{2}{|c|}{ Sistema de drenos para captar o chorume } \\
\cline { 2 - 4 } & RSH e capim seco & RSH e capim seco & RSH e capim seco \\
\hline
\end{tabular}

Fonte: Elaborada pelos autores (agosto/2015)

Cada canteiro foi construído em alvenaria (bloco de cimento) com 0,8 $\mathrm{m}$ de altura, 0,5 $\mathrm{m}$ de largura e $1 \mathrm{~m}$ de comprimento, totalizando $0,4 \mathrm{~m}^{3}$ de volume e com o piso impermeabilizado com concreto. A produção de chorume foi retida em um tanque com o fundo impermeabilizado e teve seu volume mensurado posteriormente. Os canteiros ficaram protegidos contra a incidência de raios solares diretos e chuva. No primeiro tratamento, foi utilizado RSH e serragem, na proporção de 6:1. No segundo, foi utilizada a mesma proporção do primeiro, porém o substrato foi o capim seco. Essas proporções foram definidas conforme metodologia proposta por Maragno, Trombin e Viana (2007) e adaptada para este trabalho. Após o preenchimento de cada canteiro, não ocorreu nenhuma intervenção nos canteiros por 60 dias para a formação da microbiota inicial. Após esse período, iniciaram-se reviramentos periódicos e manutenção de teores de umidade satisfatórios entre 60 e 80 \%, para a oxigenação do sistema e a sua completa estabilização.

Para a pesquisa das bactérias do grupo coliforme foram efetuadas 16 coletas em cada canteiro, totalizando 96 amostras, com intervalo semanal, sendo a primeira coleta realizada no primeiro dia da implantação. Para a análise bacteriológica foram coletadas amostras em quatro pontos da área da compostagem de cada canteiro, sendo dois na área central e os demais em dois pontos extremos do canteiro e de lados opostos.

As análises bacteriológicas foram efetuadas com o uso da técnica utilizada por Vanderzant e Splittstoesser (1992 apud SOTO et al., 2015) e Silva et al. (2007 apud SOTO et al. 2015). apud Soto et al.,(2015). Foram também analisados os seguintes parâmetros físico-químicos nos sistemas de compostagem: temperatura e produção de chorume. A temperatura foi aferida diariamente com horário pré-determinado, desde o dia zero até o $105^{\circ}$ dia do sistema. 0 chorume produzido teve o volume retido em um reservatório, medido semanalmente.

Os dados obtidos foram analisados estatisticamente em duas etapas, análise univariável e análise multivariável para a determinação da presença de coliformes. Formaram-se dois grupos de positivos e negativos na análise univariável, que foram comparados frente às variáveis analisadas. As variáveis que apresentaram valor de $p \leq 0,2$ pelo teste de qui-quadrado ou teste exato de Fisher foram selecionadas para a análise multivariável, utilizando regressão logística múltipla ((ZAR, 1999 apud SOTO et al., 2015). O nível de significância adotado foi de 5 \%, e as análises foram realizadas com o programa SPSS 20.0 for Windows.

\section{Resultados e discussão}

Os resultados da pesquisa de coliformes totais nos sistemas de compostagem tendo como substratos a serragem e o capim seco, durante as 16 avaliações efetuadas, revelaram que os valores 
se mantiveram em 240 Unidades Formadoras de Colônias (UFC)/mL nos seis canteiros, evidenciando que esses métodos foram incapazes de reduzir essas bactérias. Esses resultados foram diferentes dos de Silva et al. (2013), em experimento semelhante, porém com o uso de esterco de bovino e ovino. No trabalho de Silva et al. foram detectadas reduções de coliformes totais entre 70 e $78 \%$ no sistema de compostagem. Acredita-se que a divergência de resultados esteja relacionada aos diferentes valores de fonte de energia para atividade microbiana: esterco de animal versus $\mathrm{RSH}$, determinante para o estabelecimento da exotermia.

Na Tabela 1 estão apresentados os resultados médios obtidos para a investigação de coliformes termotolerantes associado aos substratos serragem e capim seco.

Tabela 1. Resultados médios da pesquisa de coliformes termotolerantes em UFC $1 / \mathrm{mL}^{\text {no }}$ sistema de compostagem de resíduos sólidos de hortaliças associado aos substratos: serragem e capim seco durante 105 dias de avaliação.

\begin{tabular}{cccc}
\hline \multirow{2}{*}{ Semana } & \multicolumn{3}{c}{ Coliformes Termotolerantes $(\mathrm{UFC} / \mathrm{mL})$} \\
\cline { 2 - 4 } 01 & Dia & Serragem & Capim Seco \\
\hline 02 & Zero & 240,0 & 240,0 \\
03 & 07 & 240,0 & 240,0 \\
04 & 14 & 159,7 & 85,3 \\
05 & 21 & 99,3 & 161,8 \\
06 & 28 & 165,3 & 169,7 \\
07 & 35 & 90,0 & 165,3 \\
08 & 42 & 80,0 & 240,0 \\
09 & 49 & 240,0 & 240,0 \\
10 & 56 & 240,0 & 240,0 \\
11 & 63 & 240,0 & 240,0 \\
12 & 70 & 240,0 & 240,0 \\
13 & 77 & 240,0 & 240,0 \\
14 & 84 & 240,0 & 240,0 \\
15 & 91 & 240,0 & 240,0 \\
16 & 98 & 240,0 & 240,0 \\
& 105 & 240,0 & 240,0 \\
\hline
\end{tabular}

1-Unidades Formadoras de Colônias

Fonte: Elaborada pelos autores (novembro/2015)

Em relação à pesquisa para coliformes termotolerantes, foi detectada uma queda nas UFCs da semana três até a sétima, com valores médios de 118,86 UFC/mL para o substrato constituído por serragem, e cerca de 50 \% inferior quando comparado com a primeira e segunda semana. Sá et al. (2014), que avaliaram a dinâmica da população de coliformes durante a compostagem automatizada de dejetos líquidos de suínos, tendo também como substrato a serragem, observaram redução acima de $90 \%$ de coliformes termotolerantes ao final de 156 dias.

Para o substrato constituído por capim seco, a queda nas UFC ocorreu entre a terceira e a sexta semana (Tabela 1), com valores médios de 145,25 UFC/mL e cerca de $40 \%$ inferior quando comparado com a primeira e segunda semana. Tais resultados indicaram que o substrato constituído por serragem foi capaz de manter os coliformes termotolerantes por um tempo maior e com níveis inferiores de UFC de coliformes totais. 
Entretanto, a partir da oitava semana para o canteiro constituído por substrato de serragem e da sétima semana para o canteiro constituído por capim seco, os valores de coliformes termotolerantes voltaram a subir, com níveis iguais aos detectados nas duas primeiras semanas (Tabela 1), ou seja, $240 \mathrm{UFC} / \mathrm{mL}$, o que mostrou a incapacidade dos dois métodos de manter esses micro-organismos com valores reduzidos.

Acredita-se que isto esteja relacionado principalmente ao fator temperatura (ORRICO, LUCAS JUNIOR, ORRICO JUNIOR; 2007) e material com excesso de fibra. Outro fator que pode ter contribuído para a elevação de coliformes termotolerantes é a possível contaminação por aves ou insetos artrópodes, principalmente moscas nos canteiros. Tal fator sugere que, em futuras investigações semelhantes, devem ser previstas proteções nos canteiros para evitar a presença desses animais, como o uso de telas.

$\mathrm{Na}$ análise de associação entre os canteiros constituídos pelos dois substratos não houve diferença estatística para os coliformes termotolerantes, com valor de $p=0,550$, entretanto houve diferença entre as semanas ( $p=0,0031)$.

Não houve interação entre tratamento e semanas sobre contagem de coliformes termotolerantes $(p=0,957)$.

Na Tabela 2 estão apresentados os resultados médios obtidos em relação à temperatura média no sistema de compostagem associado aos substratos serragem e capim seco.

Tabela 2. Resultados médios em relação à temperatura média em graus Celsius $\left({ }^{\circ} \mathrm{C}\right)$ no sistema de compostagem de resíduos sólidos de hortaliças associado aos substratos serragem e capim seco durante 105 dias de avaliação.

\begin{tabular}{cccc}
\hline \multirow{2}{*}{ Semana } & \multicolumn{3}{c}{ Temperatura média $\left({ }^{\circ} \mathbf{C}\right)$} \\
\cline { 2 - 4 } & Dia & Serragem & Capim Seco \\
\hline 01 & Zero & 28,33 & 23,00 \\
03 & 07 & 35,85 & 35,30 \\
04 & 14 & 24,57 & 27,23 \\
05 & 21 & 22,33 & 25,23 \\
06 & 28 & 21,61 & 20,80 \\
07 & 35 & 21,56 & 20,39 \\
08 & 42 & 21,80 & 19,71 \\
09 & 49 & 19,42 & 17,18 \\
10 & 56 & 19,71 & 15,80 \\
11 & 63 & 19,04 & 15,37 \\
12 & 70 & 18,99 & 15,56 \\
13 & 77 & 19,71 & 18,62 \\
14 & 84 & 21,07 & 17,13 \\
15 & 91 & 19,75 & 15,71 \\
16 & 98 & 19,85 & 19,52 \\
& 105 & 20,62 & 17,13 \\
\hline
\end{tabular}

Fonte: Elaborada pelos autores (novembro/2015)

Foi observada baixa temperatura nos dois tipos de substratos, a qual não ultrapassou $36{ }^{\circ} \mathrm{C}$ durante as dezesseis semanas avaliadas, o que foi incapaz de reduzir e manter UFC de coliformes termotolerantes a níveis baixos. 
O excesso de material fibroso nos dois sistemas experimentais, pobres em energia, impossibilitou o crescimento satisfatório da flora microbiana competitiva, a exotermia e o consequente aumento de temperatura. 0 maior valor de temperatura no canteiro com substrato de serragem e de capim seco foi de $35,85^{\circ} \mathrm{C}$ e $35,30^{\circ} \mathrm{C}$, respectivamente, da segunda para a terceira semana, momento em que houve redução dos coliformes termotolerantes (Tabela 1), apesar de trabalhos indicarem valores acima de $45^{\circ} \mathrm{C}$, para que isto ocorra (SANTOS; ESCOTEGUY; RODRIGUES, 2010; HECK et al., 2013). A partir da quarta semana até a décima sexta, os valores máximos foram para os canteiros com substrato de serragem e de capim seco de $22,33^{\circ} \mathrm{C}$ e $25,23^{\circ} \mathrm{C}$, respectivamente (Tabela 2 ). A temperatura mínima observada foi de $18,99^{\circ} \mathrm{C}$ e $15,37^{\circ} \mathrm{C}$ (Tabela 2) para os canteiros com substrato de serragem e de capim seco, respectivamente. Exceção somente para a temperatura mínima do canteiro com capim seco, os demais valores estiveram dentro da faixa de crescimento de micro-organismos mesófilos, que é entre 20 e $35^{\circ} \mathrm{C}$, aproximadamente, reduzindo assim o estabelecimento de uma microbiota altamente competitiva (PAREDES FILHO, 2014).

$\mathrm{Na}$ análise de associação entre os canteiros constituídos pelos dois substratos para o parâmetro temperatura houve interação significante entre tratamento e semanas sobre a temperatura ( $p<$ 0,0001).

Tanto no canteiro com substrato de capim seco quanto de serragem, obteve-se a produção de uma quantidade satisfatória de chorume, totalizando 200 litros, e volume médio de 33 L para cada $0,4 \mathrm{~m}^{3}$ de volume de material compostado. Os dois substratos foram incapazes de absorver o chorume com elevação da umidade a níveis que possam ter prejudicado a exotermia dos sistemas (PAIVA et al., 2012b).

\section{Conclusão}

Nas condições em que foi efetuado o experimento de compostagem, constituído por resíduo sólido de hortaliça, pode-se concluir que:

A utilização dos substratos serragem ou capim seco foi incapaz de reduzir coliformes totais durante 105 dias;

Entre a terceira e a sétima semana, o sistema de compostagem que teve como substrato a serragem foi capaz de reduzir em cerca de $50 \%$ os coliformes termotolerantes;

Entre a terceira e a sexta semana, o sistema de compostagem que teve como substrato o capim seco foi capaz de reduzir em cerca de $40 \%$ os coliformes termotolerantes;

Foram verificadas temperaturas inferiores a $40{ }^{\circ} \mathrm{C}$ durante as dezesseis semanas do experimento. Tais temperaturas nesta faixa possibilitaram a viabilidade de coliformes totais e termotolerantes nos sistemas de compostagem, tendo como substratos a serragem e o capim seco.

\section{Agradecimentos}

À Pró-Reitoria de Pesquisa e Inovação do Instituto Federal de Educação, Ciência e Tecnologia de São Paulo pelo apoio financeiro dado à pesquisa. 


\title{
Coliform research in a waste composting with different substrates
}

\begin{abstract}
This study aimed to evaluate the reduction or elimination of coliform bacteria in a solid waste vegetable composting system (SWV) with sawdust and dried grass substrates. There were two treatments with three replications in each. In the first treatment, SWV and sawdust were used in the proportion 6:1. In the second treatment, it was used the same proportion as the first one, however using dry grass substrate. 16 collections at each site were carried out in order to research the coliform bacteria. Temperature and production of manure were also analyzed. The results showed the use of sawdust or dried grass substrates was unable to reduce total coliforms. Between the third and seventh week, there was a reduction of approximately $50 \%$ for the coliform sawdust substrate, and between the third and sixth week, the dried grass substrate was able to reduce by approximately 40 $\%$ for the coliform. The temperatures were below $40{ }^{\circ} \mathrm{C}$ in the sixteen weeks of the experiment for both substrates.
\end{abstract}

Keywords: Total and fecal coliforms. Sawdust. Dry grass. Temperature.

\section{Referências}

BARREIRA, L. P.; PHILIPPI JUNIOR, A.; RODRIGUES, M. S. Usinas de compostagem do Estado de São Paulo: qualidade dos compostos e processos de produção. Engenharia Sanitária e Ambiental, v. 11, n. 4, p. 385-393, out./dez. 2006. Disponível em: <http://www.scielo.br/pdf/esa/v11n4/a12v11n4.pdf>. Acesso em: novembro de 2015.

GONÇALVES, V. P.; MARIN, J. M. Fate of non 0157 Shiga toxigenic Escherichia coli in composted cattle manure. Arquivo Brasileiro de Medicina Veterinária e Zootecnia, Belo Horizonte, v. 59, n. 4, p. 825-831, aug. 2007. Disponível em: <http://www.scielo.br/scielo.php?script=sci_arttext\&pi$\mathrm{d}=$ S0102-09352007000400001 >. Acesso em: novembro de 2015.

HECK, K.; DE MARCO, E. G.; HAHN, A. B. B.; KLUGE, M.; SPILKI, F. R.; VAN DER SAND, S. T. Temperatura de degradação de resíduos em processo de compostagem e qualidade microbiológica do composto final. Revista Brasileira de Engenharia Agrícola e Ambiental, Campina Grande, v. 17, n. 1, p. 54-59, jan. 2013. Disponível em: <http://www.scielo.br/scielo.php?script=sci_arttext\&pi$\mathrm{d}=$ S1415-43662013000100008>. Acesso em: novembro de 2015.

MALDONADO, C. A. B.; OMAR, D.; OLIVEIRA, E. R. de. Avaliação do processo de compostagem de podas e aparas do Campus da UFGD e estercol da criação cunícola: temperatura, umidade e pH. Cadernos de Agroecologia, v. 9, n. 4, p. 1-7, fev. 2015. Disponível em: <http://www.aba-agroecologia. org.br/revistas/index.php/cad/article/view/16728>. Acesso em: novembro de 2015.

MARAGNO, E. S.; TROMBIN, D. F.; VIANA, E. O uso da serragem no processo de minicompostagem. Engenharia Sanitária e Ambiental, Rio de Janeiro, v. 12, n. 4, p. 355-360, out./dez. 2007. Disponível em: <http://www.scielo.br/scielo.php?script=sci_arttext\&pid=\$1413-41522007000400001>. Acesso em: novembro de 2015 
ORRICO, A. C.; LUCAS JUNIOR, J. de; ORRICO JUNIOR, M. A. P. Alterações físicas e microbiológicas durante a compostagem dos dejetos de cabras. Engenharia Agrícola, v. 27, n. 3, p. 764 772, set./dez. 2007. Disponível em: <http://www.scielo.br/scielo.php?script=sci_arttext\&pi$\mathrm{d}=$ S0100-69162007000400020\&Ing=en\&nrm=iso\&tIng=pt $>$. Acesso em: novembro de 2015.

PAIVA, E. C. R.; MATOS, A. T. de; AZEVEDO, M. A.; BARROS, R. T. P. de; COSTA, T. D. R. Avaliação da compostagem de carcaças de frango pelos métodos da composteira e de leiras estáticas aeradas. Engenharia Agrícola, Jaboticabal, v. 32, n. 5, p. 961-970, set./out. 2012a Disponível em: <http://www.scielo.br/scielo.php?script=sci_arttext\&pid=S0100-69162012000500015\&lng=en\&nrm=iso\&tlng=pt $>$. Acesso em: novembro de 2015.

PAIVA, E. C. R.; MATOS, A. T. de; SARMENTO, A. P.; PAULA, H. M. de; JUSTINO, E. A. Avaliação de sistema de tratamento de carcaças de frangos pelo método da composteira-windrow. REEC-Revista Eletrônica de Engenharia Civil, Goiânia, v. 3, n. 1, p. 19-27, 2012b. Disponível em:<https://www. revistas.ufg.br/reec/article/view/16820 > . Acesso em: novembro de 2015.

PAREDES FILHO, M. V. Utilização de micro-organismos eficazes no processo de compostagem. 2014. 65 f. Dissertação (Mestrado Profissional em Sistemas de Produção na Agropecuária) - Universidade de Alfenas, Alfenas (MG), 2014.

RODRIGUES, P. N.; ROLIM, M. M.; BEZERRA NETO, E.; COSTA, R. N. T.; PEDROSA, E. M. R.; OLIVEIRA, V. S. Efeito do composto orgânico e compactação do solo no milho e nutrientes do solo. Revista Brasileira de Engenharia Agrícola e Ambiental, Campina Grande, v. 15. n. 8, p.788-793, ago./2011. Disponível em: <http://www.scielo.br/scielo.php?script=sci_arttext\&pi$\mathrm{d}=$ S1415-43662011000800004 > . Acesso em: novembro de 2015.

SÁ, M. F.; AITA, C.; DONEDA, A.; PUJOL, S. B; CANTÚ, R. R.; JACQUES, I. V. C.; BASTIANI, G. G.; OLIVEIRA, P. D.; LOPES, P. D. Dinâmica da população de coliformes durante a compostagem automatizada de dejetos líquidos de suínos. Arquivo Brasileiro de Medicina Veterinária e Zootecnia, Belo Horizonte, v. 66, n. 4, p. 1.197-1.206, ago/2014. Disponível em: <http://www.scielo.br/scielo. php?script=sci_arttext\&pid=S0102-09352014000401197>. Acesso em: novembro de 2015.

SANCHUKI, C. E.; SOCCOL, C. R.; CARVALHO, J. C. de; SOCCOL, V. T.; NASCIMENTO, C. do; WOICIECHOWSKI, A. L. Evaluation of poultry litter traditional composting process. Brazilian Archives of Biology and Technology, Curitiba, v. 54, n. 5, p. 1053-1058, set./out.2011. Disponível em: $<$ http://www.scielo.br/scielo.php?script=sci_arttext\&pid=S1516-89132011000500024>. Acesso em: novembro de 2015.

SANTOS, F. G. D.; ESCOSTEGUY, P. A. V.; RODRIGUES, L. B. Qualidade de esterco de ave poedeira submetido a dois tipos de tratamentos de compostagem. Revista Brasileira de Engenharia Agrícola e Ambiental, Campina Grande, v. 14, n. 10, p. 1101-1108, out. 2010. Disponível em: <http://www. scielo.br/scielo.php?pid=S1415-43662010001000012\&script=sci_abstract\&tlng=pt $>$. Acesso em: novembro de 2015.

SILVA, R. F. D.; VASCONCELLOS, N. J. S. de; STEFEN, G. P. K.; DOTTO, R. B.; GRUTKA, L. Caracterizações microbiológicas e químicas em resíduos orgânicos submetidos à vermicompostagem. Current Agricultural Science and Technology, v. 17, n. 1, p. 108-115, jan./mar. 2011. Disponível em: <https://periodicos.ufpel.edu.br/ojs2/index.php/CAST/article/view/2037> . Acesso em: novembro de 2015. 
SILVA, N.; JUNQUEIRA, V. C. A.; SILVEIRA, N. F. A.; TANIWAKI, R. H.; SANTOS, R. F. S. dos; GOMES, R. A. R.; OKAZAKI, M. M. Manual de métodos de análises microbiológicas de alimentos. 3. ed. São Paulo: Livraria Varela, 2007. 119-129 p.

SOTO, F. R. M.; SILVA, M. O.; MORAES, R.; CRUZ; J. V.; CAVALCANTI, J. P.; SILVA, F. A.; LIMA, L. R.; JESUS, E. S.; AZEVEDO, S. S.; DUARTE, I. P.; ALMEIDA, M.; GAZZINELLI, S. E. P. Physical, chemical, microbiological and parasitological parameters in a composting system of vegetable solid residues. American Journal Enviromental Sciences, v. 11, n. 6, p. 420-426, 2015.

SUNADA, N. D. S.; ORRICO, A. C. A.; ORRICO JUNIOR, M. A. P.; CENTURION, S. R.; OLIVEIRA, A. B. M.; FERNANDES, A. R. M.; LUCAS JUNIOR, J. de; SENO, L. O. Compostagem de resíduo sólido de abatedouro avícola. Ciência Rural, Santa Maria, v. 45, n. 1, p. 178-183, jan. 2015. Disponível em: <http://www.scielo.br/pdf/cr/v45n1/0103-8478-cr-0103-8478cr20120261.pdf>. Acesso em: novembro de 2015.

VALENTE, B. S.; XAVIER, E. G.; MORAES, P. O.; MANZKE, N. E.; ROLL, V. F. B. Eficiência do SISCODE e da aeração passiva no tratamento de resíduos da produção animal no município de Capão do Leão/RS. Revista Engenharia Sanitária e Ambiental, Rio de Janeiro, v. 16, n. 3, p. 231-236, jul./set. 2011. Disponível em: <http://www.scielo.br/scielo.php?script=sci_arttext\&pi$\mathrm{d}=$ S1413-41522011000300005\&lng=en\&nrm=iso\&tlng=pt>. Acesso em: novembro de 2015.

VALENTE, B. S.; XAVIER, E. G.; PEREIRA, H. S.; PILOTTO, M. V. T. Compostagem na gestão de resíduos de pescado de água doce. Boletim Instituto de Pesca, São Paulo, v. 40, n. 1, p. 95-103, 2014. Disponível em: <http://revistas.bvs-vet.org.br/bolinstpesca/article/view/34537>. Acesso em: novembro de 2015.

VANDERZANT, C.; SPLITTSTOESSER, D. F. Compendium of methods for microbiological examination for foods. 3. ed. Washington: American Public Health Association, 1992. p. 325-367.

HITCHINS, A.; HARTMAN, P. A.; TODD, E. C. D. Coliforms : escherichia coli and its toxins. In: VANDERZANT, C., SPLITTSTOESSER, D. F. (Eds.). Compendium of methods for the examination of foods. Washington: American Public Health Association, 1992. p. 325-367.

ZAR J. H. Biostatistical analysis. 4. ed. Prentice-Hall, New Jersey. 663P, 1999.

\section{Histórico editorial:}

Submetido em: 29/02/2016

Aceito em: 20/06/2016 
Como citar:

$\underline{A B N T}$

SOTO, F. R. M.; MOURA, S. L. de; NÓBREGA, L. P.; AZEVEDO, S. S. de. Pesquisa de coliformes em compostagem de resíduos de hortaliças com a utilização de diferentes substratos. Revista Agrogeoambiental, Pouso Alegre, v. 9, n. 2, p. 117-125, abr./jun. 2017. Doi: http://dx.doi.org/10.18406/2316-1817v9n22017951

$\underline{A P A}$

SOTO, F. R. M., MOURA, S. L. de, NÓBREGA, L. P. \& AZEVEDO, S. S. de. (2017). Pesquisa de coliformes em compostagem de resíduos de hortaliças com a utilização de diferentes substratos. Revista Agrogeoambiental, Pouso Alegre, 9 (2), 117-125. Doi: http://dx.doi.org/10.18406/2316-1817v9n22017951

$\underline{\text { ISO }}$

SOTO, F. R. M.; MOURA, S. L. de; NÓBREGA, L. P. e AZEVEDO, S. S. de. Pesquisa de coliformes em compostagem de resíduos de hortaliças com a utilização de diferentes substratos. Revista Agrogeoambiental, 2017, vol. 9, n. 2, pp. 117-125. Eissn 2316-1817. Doi: http://dx.doi.org/10.18406/2316-1817v9n22017951

\section{VANCOUVER}

Soto FRM, Moura SL de, Nóbrega LP, Azevedo SS. Pesquisa de coliformes em compostagem de resíduos de hortaliças com a utilização de diferentes substratos. Rev agrogeoambiental. 2017 abr/jun; 9(2): 117-125. Doi: http://dx.doi.org/10.18406/2316-1817v9n22017951 